\title{
Amyloid Formation on Lipid Membrane Surfaces
}

\author{
Paavo K.J. Kinnunen* \\ Helsinki Biophysics and Biomembrane Group, Medical Biochemistry/Institute of Biomedicine, University of Helsinki, \\ Finland
}

\begin{abstract}
Several lines of research have concluded lipid membranes to efficiently induce the formation of amyloid-type fibers by a number of proteins. In brief, membranes, particularly when containing acidic, negatively charged lipids, concentrate cationic peptides/proteins onto their surfaces, into a local low $\mathrm{pH}$ milieu. The latter together with the anisotropic low dielectricity environment of the lipid membrane further forces polypeptides to align and adjust their conformation so as to enable a proper arrangement of the side chains according to their physicochemical characteristics, creating a hydrophobic surface contacting the lipid hydrocarbon region. Concomitantly, the low dielectricity also forces the polypeptides to maximize intramolecular hydrogen bonding by folding into amphipathic $\alpha$-helices, which further aggregate, the latter adding cooperativity to the kinetics of membrane association. After the above, fast first events, several slower, cooperative conformational transitions of the oligomeric polypeptide chains take place in the membrane surface. Relaxation to the free energy minimum involves a complex free energy landscape of the above system comprised of a soft membrane interacting with, and accommodating peptide polymers. The overall free energy landscape thus involves a region of polypeptide aggregation associated with folding: polypeptide physicochemical properties and available conformation/oligomerization state spaces as determined by the amino acid sequence. In this respect, of major interest are those natively disordered proteins interacting with lipids, which in the absence of a ligand have no inherent structure and may adapt different functional states. Key sequence features for lipid and membrane interactions from the point of view of amyloid formation are $i$ ) conformational ambiguity, ii) adoption of amphipathic structures, iii) ion binding, and $i v$ ) propensity for aggregation and amyloid fibrillation.

The pathways and states of the polypeptide conformational transitions further depend on the lipid composition, which thus couples the inherent properties of lipid membranes to the inherent properties of proteins. In other words, different lipids and their mixtures generate a very complex and rich scale of environments, involving also a number of cooperative transitions, sensitive to exogenous factors (temperature, ions, $\mathrm{pH}$, small molecules), with small scale molecular properties and interactions translating into large scale 2- and 3-D organization. These lipid surface properties and topologies determine and couple to the transitions of the added polypeptide, the latter now undergoing oligomerization, with a sequence of specific and cooperative conformational changes.

The above aggregation/folding pathways and transient intermediates of the polypeptide oligomers appear to have distinct biological functions. The latter involve $i$ ) the control of enzyme catalytic activity, ii) cell defence (e.g. antimicrobial and cancer killing peptides/proteins, as well as possibly also iii) control of cell shape and membrane traffic. On the other hand, these processes are also associated with the onset of major sporadic diseases, all involving protein misfolding, aggregation and amyloid formation, such as in Alzheimer's and Parkinson's diseases, prion disease, and type 2 diabetes. Exemplified by the latter, in an acidic phospholipid containing membrane human islet associated polypeptide (IAPP or amylin, secreted by pancreatic $\beta$-cells) efficiently transforms into amyloid $\beta$-sheet fibrils, the latter property being associated with established sequence features of IAPP, involved in aggregation and amyloid formation. IAPP sequence also harbors anion binding sites, such as those involving cationic side chains and $\mathrm{N}$-terminal $\mathrm{NH}$-groups of the $\alpha$-helix. The association with acidic lipids neutralizes 'gatekeeping' cationic residues, abrogating electrostatic peptide-peptide repulsion. The subsequent aggregation of the $\alpha$-helices involves further oligomerization and a sequence of slow transitions, driven by hydrogen bonding, and ending up as amyloid $\beta$-sheet fibrils. Importantly, the above processing of IAPP in its folding/aggregation free energy landscape under the influence of a lipid membrane involves also transient cytotoxic intermediates, which permeabilize membranes, allowing influx of $\mathrm{Ca}^{2+}$ and triggering of cell death, this process resulting in the loss of $\beta$-cells, seen in type 2 diabetes. Similar chains of events are believed to underlie the loss of tissue function in the other disorders mentioned above.
\end{abstract}

Keywords: Lipid-protein interactions, amyloid, host defense proteins, membranes, acidic phospholipids, oxidized lipids.

\section{INTRODUCTION}

Amyloid formation contributes as a molecular level mechanism to the development of a number of major

*Address correspondence to this author at the Helsinki Biophysics \& Biomembrane Group, Medical Biochemistry/Institute of Biomedicine, P.O. Box 63 (Haartmaninkatu 8), FIN-00014, University of Helsinki, Finland; Tel: +358 9 19125400; Fax: +328 9 19125444;

E-mail: paavo.kinnunen@helsinki.fi ailments, such as Alzheimer's and Parkinson's disease, type 2 diabetes, and prion disease [1]. In each of the above conditions specific peptide(s) (i.e. $A \beta /$ tau, $\alpha$-synuclein, IAPP, and $\operatorname{PrP}$, respectively) aggregate(s) into fibrillar cross $\beta$-sheet structures, with concomitant cell death leading to loss of tissue function. The cytotoxicity of fibrils has been recognized to be associated with an intermediate oligomer, a metastable 'protofibril', existing transiently in the peptide aggregation/folding pathways, ending up as the so-called mature 
and non-toxic, inert amyloid, the latter corresponding to the minimum in the free energy landscape. The primary mechanism of cytotoxicity of the 'protofibrils' has been concluded to be the permeabilization of cell membranes, allowing uncontrolled flow of ions, most notably $\mathrm{Ca}^{2+}$ into the cell, further leading to cell death. While mitochondrial membranes could also be directly affected by the protofibrils, the influx of $\mathrm{Ca}^{2+}$ suffices in triggering the permeability transition of the mitochondrial membrane, with extensive generation of reactive oxygen species (ROS) and release of cytochrome c launching further events downstream in the apoptotic program $[2,3]^{1}$.

The conditions triggering amyloid formation in the above sporadic diseases have been intensively studied. Importantly, in most cases of Alzheimer's disease there is no aggravating mutation in the $A \beta$ peptide [5]. Furthermore, also for the cases with a recognized mutation this disorder manifests just in middle age. Similar conclusions are valid also for type 2 diabetes, with a number of disposing factors such as obesity and lack of exercise, while the sequence of the IAPP peptide bears no mutation. Accordingly, the role of environment in controlling amyloid formation appears to be decisive in determining the onset of these disorders. The key question concerns the molecular mechanisms involved.

Accelerated amyloid formation in vitro in the presence of lipid membranes has been reported for the above disease associated amyloid forming peptides [6-8] as well as a plethora of other cytotoxic and apoptotic proteins and peptides [9-11]. Accordingly, from the point of view of understanding amyloid formation the lipid environment appears to be of particular relevance for two reasons: lipid membranes of proper composition and physical properties trigger the formation of toxic oligomers, which simultaneously compromise the permeability barrier function of these lipid bilayers. The mechanisms triggering amyloid oligomerization on lipid membrane surfaces are thus closely linked to the mechanisms of cytotoxicity. Analysis of the relevant properties of lipid bilayers and biomembranes, characteristics of membrane association of amyloidogenic polypeptide chains, and the sequence characteristics of these polypeptides, together with the molecular level processes involved in cytotoxicity reveal these processes to involve a number of generic features.

More recently it has also become evident that amyloid formation is utilized by organisms for beneficial purposes. Along these lines we will go through examples of the roles of lipid surfaces in triggering functional amyloid-type oligomerization in cells, such as suggested for a) host defence peptides, killing cancer cells and microbes, as well as $b$ ) acting as an on-off switch controlling the activity of a lipid associated enzyme. It is further possible that a similar membrane-associated protein oligomerization process could be used to c) drive intracellular membrane traffic and outgrowth of cellular extensions such as neurites.

\footnotetext{
${ }^{1}$ In this context it is important to distinguish these cases from systemic amyloidoses, where tissue and organ functions deteriorate due to obstruction caused by extensive accumulation of amyloid mass [4].
}

\section{BIOPHYSICAL CHARACTERISTICS OF LIPID SURFACES}

For a number of decades and in particular in the frenzy of the 'postgenomic era' lipids were considered by most life scientists to be insignificant to the development of our understanding of the essential features and pathophysiology of living organisms, such as their subcellular organization and control of cell behaviour, differentiation and metabolism, with overtly dominant roles assigned to proteins, genetics, and control of gene expression. As a consequence, the per se interesting properties of lipids were explored mainly by physicists, physicochemists, and surface chemists. Starting from these disciplines and over the years this area developed and matured to one of the main stream topics in modern biophysics. Being heavily influenced by physics this research became also very much concept driven, in distinction from the distinctively method driven life sciences such as molecular and cell biology. Further, the terminology adapted to describe membrane biophysical properties developed complexity and sophistication, which made this research difficult to access by an average life scientist. A profound example of the consequences of this barrier is the rediscovery of membrane 'rafts' by cell biologists, assigning a new name to lipid microdomains [12], demonstrated long ago by biophysicists [13-16].

Lipids are by far the chemically most diverse class of biomaterials. Based on lipidomics analyses an average eukaryote cell can now be estimated to contain not thousands but tens of thousand of different lipids, with specific compositions found in different cell types as well as in different cellular organelles. These compositions are highly dynamic, adapting on different time scales to both physiological and pathological changes in the organism (e.g. [17]). Assembled together with membrane proteins into biomembranes, the latter structures possess an enormous number of degrees of freedom for their organization. In this regard it must be kept in mind that it is still only a very limited view, which we have on the structural features of a generic biomembrane, connected to its multitude of functions. In the following we will summarize some of the biophysical characteristics of lipid bilayers, more specifically those with unequivocal evidence demonstrated for relevance to protein interactions with membranes, as connected to amyloid formation and toxicity. For more detailed account the interested reader is referred to recent monographs (e.g. [18]).

\section{Divided Nature: Amphiphilicity}

Several of the key properties of lipid bilayers derive from the amphiphilic character of biomembrane lipids, combining a polar, hydrophilic moiety with a hydrophobic part. As a drastic consequence of this molecular scale polarity, the strong hydrogen bonding between water molecules expels the non-polar lipid acyl chains and drives phospholipids, the main lipid constituents of biomembranes, to spontaneously organize into bilayers. This process is generic to amphiphiles and represents the paradigm for hydrophobicity driven selfassembly, extending from molecular dimensions to microscopic scale. In the resulting assemblies the interactions between the amphiphiles are non-covalent and generally 
weak $^{2}$, allowing rapid rotational and lateral diffusion, together with a high degree of conformational flexibility of lipids due to intense trans-gauche bond rotations of their acyl chains. Another important mechanical property to keep in mind is the high elasticity, softness of the bilayer [18] which allows for intense Brownian undulations of the surface [20]. As we shall see below, continuing the examination of the physical characteristics of bilayers reveals how the amphiphilic character of lipids in fact underlies all the key features of membranes, imposed by the strict parallel alignment of lipids (orientational anisotropy). Notably, the amphiphilicity also involves hydrophilicity of the headgroup. The latter is much more than just simple 'water solubility' of the headgroup, and for instance for phosphatidylcholine dynamic arrangement of water molecules into several distinct hydration shells has been demonstrated, these water molecules exchanging with the bulk water on different timescales [21]. While the hydration properties of lipids is, at the end, likely to be important to also the subject area of this brief review, amyloid formation induced by lipids, it represents a topic which still awaits to be addressed.

\section{Membrane Lateral Pressure Profile}

On a conceptual level a very useful picture highlighting some of the important characteristics of a lipid bilayer is its lateral pressure profile (Fig. 1), depicting the forces parallel to the plane of the membrane as a function of distance from the bilayer centre. Three forces need to be considered, while the net force remaining must be zero so as to keep the system stable. More specifically, approaching the membrane surface from the bulk aqueous phase there is (i) a steric repulsion between the lipid headgroups, which together with (ii) the entropic repulsion due to the intense thermal motion of the acyl chains inside the bilayer balance (iii) the cohesive force, interfacial tension arising from the hydrophobic effect: the unfavourable contacts between the hydrocarbon chains and water in terms of free energy.

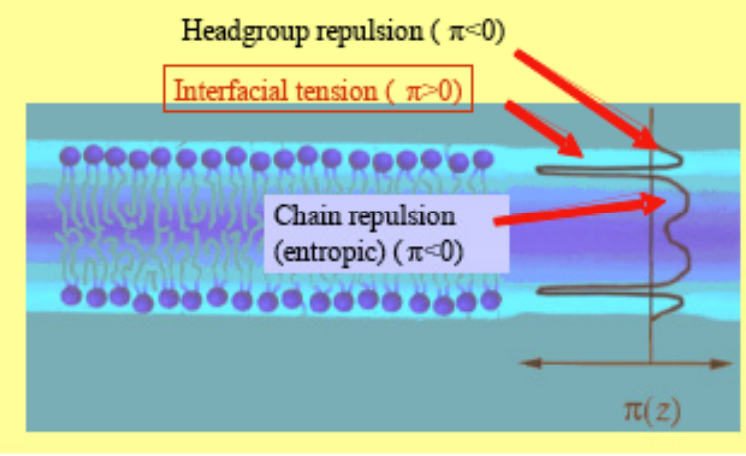

Fig. (1). Lateral pressure profile for a phospholipid bilayer. Adapted from [22].

At equilibrium the membrane is tension free, with the packing density corresponding to an equilibrium lateral pressure of approx. $32-34 \mathrm{mN} / \mathrm{m}$, a value verified for biological membranes [22]. However, membrane tension can be

\footnotetext{
${ }^{2}$ As a dramatic example of the consequences of intermolecular hydrogen bonding is the phase segregation of ceramide, occurring for example subsequent to the formation of this lipid from sphingomyelin by sphingomyelinase [19].
}

imposed by e.g. swelling by osmotic pressure gradients of cells and organelles such as mitochondria. Under the latter conditions the lateral packing density decreases, causing an increase in the interfacial tension, the membrane exposing more hydrophobic surface. This provides also an example of converting a physical force directly to a biochemical signal, as the resulting decrease in lipid lateral packing and increase in membrane hydrophobicity strongly enhance membrane partitioning of e.g. amphiphilic proteins present in the surrounding aqueous phase $[22,23]$.

An important feature of the lateral pressure profile is that it can be influenced by the shape of the amphiphiles introduced into the bilayer. Accordingly, in addition to shrinking and swelling of a cell due to osmotic pressure gradients, the membrane lateral pressure profile can be modulated by a number of factors, such as charges and intermolecular hydrogen bonding, together with the molecular shapes of the lipids (as well as proteins and bilayer partitioning small molecules). To this end, it is the effective molecular shape we need to consider [24], which involves e.g. the size of the headgroup hydration shell controlled by osmotic pressure $[25,26]$, together with the steric constraints arising from conformational entropy and unsaturation of the acyl chains (Fig. 2). Conical lipids such as lysoPC, with a single acyl chain decrease pressure in the membrane interior increasing membrane positive curvature. Positive spontaneous curvature has been demonstrated to promote amyloid oligomerization [27]. Instead, lipids such as POPE bearing a weakly hydrated, small headgroup and having thus an effective shape of a wedge reduce pressure on the headgroup level, with augmented packing in the bilayer hydrocarbon region (negative spontaneous curvature). A membrane containing e.g. PE with unsaturated chains harbours a high internal pressure and is thus described as 'frustrated' [28]. This internal pressure is inherent to all lipids favouring the formation the so-called inverted hexagonal phase $\mathrm{H}_{\mathrm{II}}$ and has important consequences in terms of bilayer-protein interactions as well as membrane fusion $[29,30]$. Last but not least, of particular interest is cholesterol, which generally augments lipid lateral packing by highly cohesive interactions, in particular with lipids having saturated acyl chains, forming what is called the liquid ordered $\left(l_{0}\right)$ phase [31]. As a consequence, cholesterol - in particular in combination with sphingomyelin - very efficiently attenuates membrane partitioning and intercalation of amphipathic peptides $[32,33]$.
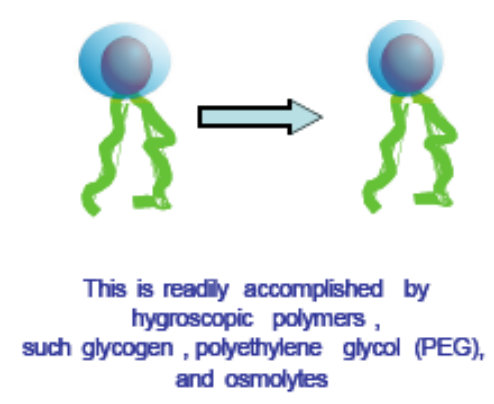

Fig. (2). Dynamic effective shape of a phospholipid, exemplified by changing its hydration shell by osmotic pressure. Adapted from [24]. 


\section{Membrane Charges and Surface pH}

The lateral pressure profile includes two important parameters influencing the membrane partitioning of an amphiphilic peptide: hydrophobicity (interfacial tension) of the surface, which provides the sole driving force in the absence of e.g. electrostatic interactions, and lipid lateral packing density, which together control the intercalation of a peptide into the bilayer. A third parameter of profound importance is membrane charge. While cationic lipids such as sphingosine $[34,35]$ are present in membranes, much more common are phospholipids having a net negative charge, such as phosphatidylserine and -glycerol, phosphatidylinositols, phosphatidic acid, cardiolipin, bis-monoacylglycerophosphate, ceramide-1-phosphate and free fatty acids. Apart from their inherent effective molecular shapes the introduction of charges has several consequences, further depending on the charge density per unit area [36]. Notably, a negatively charged membrane not only attracts positively charged counterions $\left(\mathrm{Na}^{+}, \mathrm{K}^{+}, \mathrm{Ca}^{2+}, \mathrm{Mg}^{2+}\right)$ but also $\mathrm{H}^{+}$, thus effectively lowering the $\mathrm{pH}$ on the membrane surface [37], with the bulk $\mathrm{pH}$ remaining unaffected in a buffered medium. This effect is not insignificant and it has been calculated that for a membrane containing $20 \mathrm{~mol} \%$ of cardiolipin, the $\mathrm{pH}$ prevailing on the surface can reach values in the range of 5.2 to 5.5 , confined to the immediate vicinity of the interface, readily reflected in the mode of electrostatic peripheral membrane association of proteins [38]. Increasing charge density will lower the local $\mathrm{pH}$ further. The effect however, is complex and non-linear and depends on the counterion species [39]. In order to reduce lateral Coulombic repulsion between the negatively charged phosphates, the latter protonate, which then allows for intermolecular hydrogen bonding between the phosphates of nearest neighbour lipids. This effect manifests in the at first glance counterintuitive slowing down of the rate of membrane binding of a cationic protein upon increasing the content of an acidic phospholipid in a membrane [40]. As mentioned above, anionic phospholipids enhance amyloid fibril formation. This is a central theme in this review and we will dwell on this in a number of contexts below.

\section{Membrane Polarity Gradient}

The non-covalent nature of lipid bilayer assemblies allows for intense fluctuations of the membrane and its
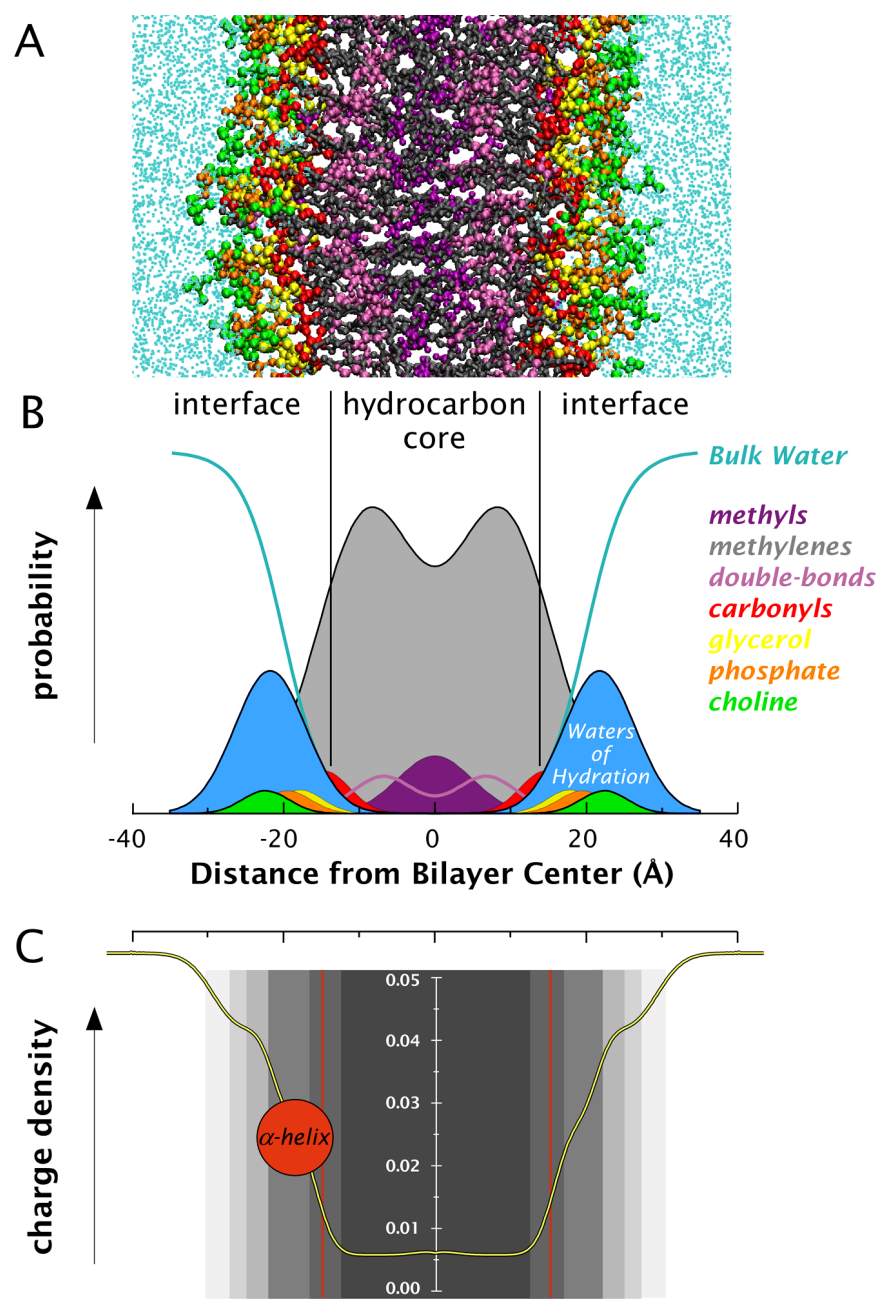

Fig. (3). Polarity gradient for a lipid bilayer. Uppermost panel A depicts a snapshot from a computer simulation of a lipid bilayer, while the middle panel B illustrates the time averaged distribution of the various chemical groups. The lowermost panel C shows the position of an amphipathic $\alpha$-helix residing in the interface, together with the gradient of the membrane polarity. See text for details (from [41] with permission). 
constituent lipids, yielding another dynamic feature, the dielectricity (polarity) gradient (Fig. 3), superimposed with the lateral pressure profile. The dielectric constant $\varepsilon$ of bulk water is 80 . Upon reaching the membrane surface and entering the bilayer interior, the polarity decreases rapidly, to approx. $\varepsilon=2$ in the hydrocarbon region. This polarity gradient parallels the steeply declining number of water molecules transiently escaping from the bulk into the bilayer. The polarity gradient is highly dynamic and is also sensitive to chemical modification of the lipids, such as those introduced by oxidation of polyunsaturated acyl chains and cholesterol, when exposed to ROS. Together, (i) the effects of membrane charges, (ii) the lateral pressure profile, and (iii) the polarity gradient yield an already quite comprehensive overall picture of the inherent characteristics of a lipid bilayer. Yet, it needs to be emphasized that a more detailed picture of the bilayer would need to include also membrane potential and dipole potential, which both exert significant impact on the state of the bilayer and its interactions with proteins and small molecules (e.g. [42-44]). Accordingly, although this area remains, as far as this author is aware of, to be explored, these properties can be readily expected to influence also amyloid formation in membranes.

\section{Lipid Asymmetry and Membrane Microdomains}

The most prevalent negatively charged lipid in the plasma membrane of eukaryote cells is phosphatidylserine, PS, comprising approx. $20 \mathrm{mo} \%$ of the total lipid in this membrane. Normally, this lipid is actively confined to reside solely in the inner, cytoplasmic leaflet of the plasma membrane lipid bilayer, and is only present in the outer surface in conditions such as apoptosis and cancer [45]. This loss of PS asymmetry has important functional consequences and for example in apoptotic cells PS exposed on the plasma membrane outer surface targets these cells to macrophages.

In addition to the above lipid asymmetry it was concluded from biophysical studies conducted in the 1970ies that membranes are heterogeneous also in terms of their lateral organization $[13,14]$. This heterogeneity results from both lipid-lipid and lipid-protein interactions acting in unison, unavoidably manifesting in the generation of a complex array of highly dynamic, fluctuating lateral heterogeneities on different time- and lengthscales, further influenced by the compositions of different cellular organelles and the generically non-equilibrium nature of biomembranes in live cells (Fig. 4). Several mechanisms have been described in vitro, such as elastic strain due to hydrophobic matching in lipidlipid and lipid-integral membrane protein interactions [46, 47] osmotic pressure [48], electrostatic attraction between clusters of cationic residues in peripheral proteins and membrane negatively charged lipids [49], as well as anionic lipids and polyamines [50], and $\mathrm{Ca}^{2+}[51]$. Concomitantly with the above, the major driving force for lateral structuring relates to the phase behaviour of lipid mixtures. These are best understood in terms of their phase diagrams, depicting the thermal behaviour of multicomponent membranes and it is now evident that for some lipid mixtures long term lateral segregation into relatively large domains is possible within the environment encountered in cellular membranes. Of particular current interest are mixtures involving ceramide as well as sterols with sphingomyelins and phosphatidylcholines [52-54] where lipid-lipid interactions, hydrogen bonding [55] and hydrophobic matching condition [56] cause the appearance of coexisting lipid phases, important to the formation of microdomains ('rafts') in biomembranes [16].

To conclude at this stage, biophysical properties of membranes and their highly dynamic organization and lateral heterogeneity provide an extremely rich range of environments in biomembranes, influencing the folding as well as misfolding of proteins and peptides. Yet, we are still in the very early phase of exploration of the coupling between these membrane properties and the conformational/functional space of membrane associated proteins.

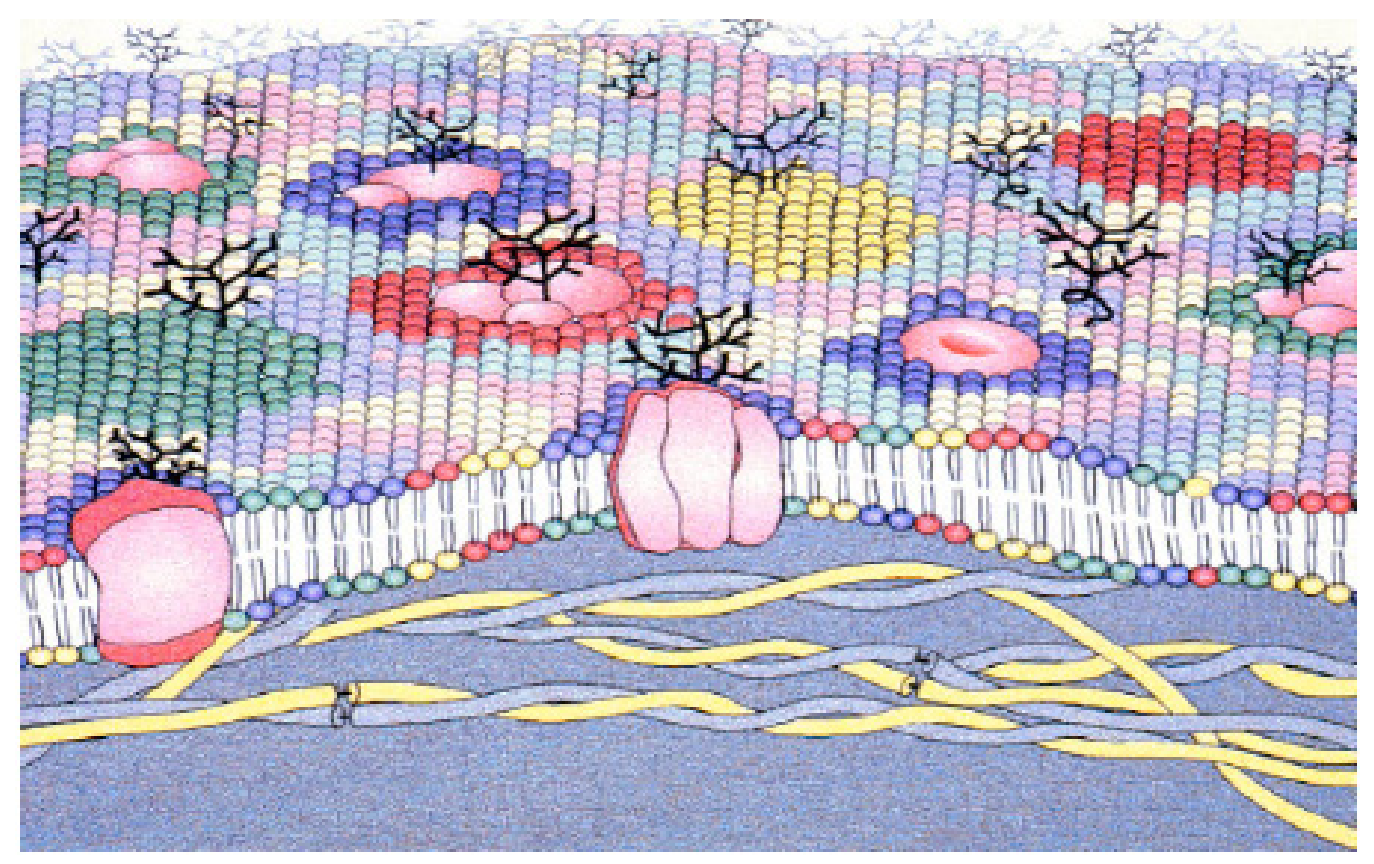

Fig. (4). Schematic illustration of the lateral heterogeneity of a biomembrane, arising from preferred lipid-protein and lipid-lipid interactions. 


\section{AMYLOID FORMATION IN A LIPID MEMBRANE}

The above properties of lipid bilayers mean that a negatively charged membrane very efficiently attracts cationic proteins to its surface, where they enter a local low $\mathrm{pH}$ environment, immediately adjacent to a low dielectric hydrocarbon region. The dynamic nature of the lipid bilayer with intense compositional and conformational fluctuations allows both the lipids and the approaching polypeptide chain to mutually adjust their conformations and positions in the surface, so as to accommodate the protein into this complex environment. Notably, the conditions prevailing on the membrane surface correspond closely to those found in vitro to yield reproducible formation of amyloid in bulk solutions, viz. acidic $\mathrm{pH}$ of 5.5 and low dielectricity (20 to $30 \%$ TFE, [57]), in agreement with the accelerated formation of amyloid fibrils in vitro in the presence of membranes containing negatively charged lipids reported for $\mathrm{A} \beta, \alpha$-synuclein, IAPP, and PrP. The enhanced formation of amyloid fibrils in the presence of negatively charged liposomes is not limited to the above peptides but is observed also for insulin, cytochrome c, endostatin, lysozyme, glyceraldehyde-3-phosphate dehydrogenase (GAPDH), and $\alpha$-lactalbumin, as well as several host defence peptides, including LL-37. In several cases the fibers have been shown to also incorporate phospholipid [9,10,33,58-60].

In distinction from the kinetics of amyloid formation in bulk low $\mathrm{pH}$ solution containing TFE, taking several hours, the formation of amyloid in the presence of lipid surfaces is significantly faster. Several factors contribute to this acceleration, as follows (Fig. 5).

i) Membranes concentrate the reacting amyloidogenic protein to the interface and this concentrating effect can be augmented by an electrostatic attraction between the anionic lipids and cationic amino acids residues and their clusters in the polypeptide chain.

ii) The lipid surface is a highly anisotropic environment, orienting the binding proteins so as to accommodate their hydrophobic parts to contact the lipid hydrocarbon chains while keeping their charged, hydrophilic domains on the membrane surface and in contact with the aqueous phase.

iii) Simultaneously with a protein entering the membrane interfacial environment, conformational changes become necessary, as the polypeptide chain is now forced to seek for new minima in the terrain opened by the lipid surface in the folding/aggregation free energy landscape. Good examples are peptides such as IAPP and temporins, which have random conformation in solution but adopt an amphipathic $\alpha$ helical conformation upon binding to phosphatidylcholine membranes $[6,8,11]$. The major driving force for the random coil $->\alpha$-helix conformational change derives from the high cost dehydrating the peptide chain hydrogen bonds upon entering the low dielectric milieu in the bilayer, avoided by the formation of intramolecular hydrogen bonds in the helix [41]. Importantly, the change from coil to $\alpha$-helix is very rapid, commencing in approx. $10^{-5} \mathrm{sec}$ [61]. Helix formation is likely being promoted also by the formation of an anion binding site by the end of the helix N-terminus, constituted by two to three NHmoeities [62].

iv) The strict alignment of polypeptide chains in the anisotropic membrane surface facilitates oligomerization and the latter is further enhanced by neutralization of the cationic charges of the protein by association with the anionic membrane lipids, thus promoting aggregation. Oligomerization has been shown for IAPP already for the $\alpha$-helical peptide chains [63]. The latter is of particular interest as recent studies suggest $\alpha$-helical conformation to represent an obligatory intermediate in the formation of amyloid by some peptides [64,65]. The inclusion of acidic phospholipids into a membrane consisting of zwitterionic PC could alter the alignment of the peptide from antiparallel to parallel [66]. Again, free energy gain results from the formation of intermolecular hydrogen bonds in a membrane environment [67]. Although amyloid fibril formation can be significantly enhanced by lipid surfaces, the sigmoidal kinetics are mostly retained, revealing nucleation to be required for triggering the involved phase transition [61].

v) Connected to membrane induced conformational changes and/or oligomerization the polypeptide chains can also change their orientation from parallel to perpendicular with the respect to the bilayer plane, intercalating into the bilayer. This process depends on the physicochemical characteristics of the bilayer (such as the lateral pressure profile and lipid packing

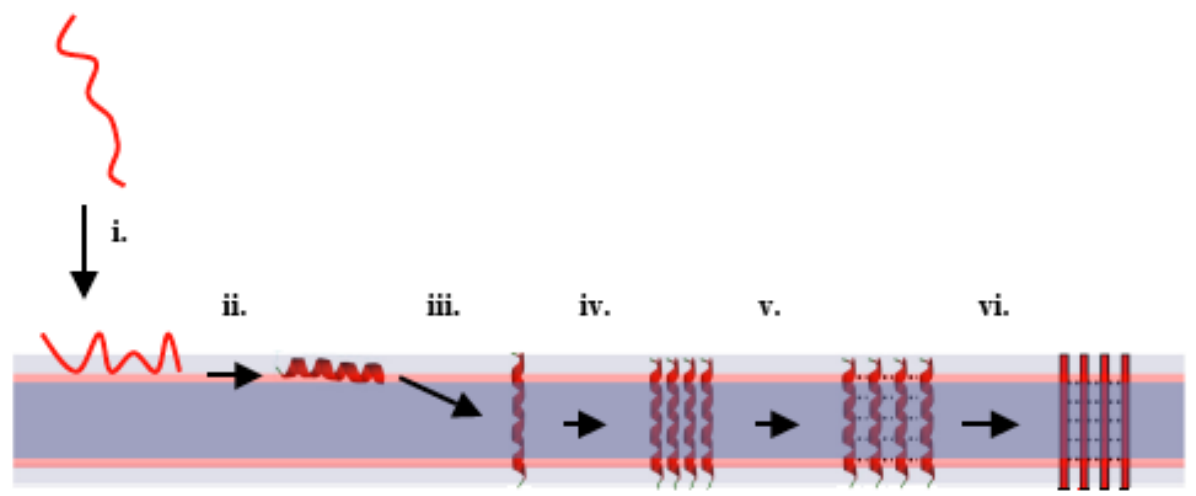

Fig. (5). Peptide binding to a lipid bilayer, with subsequent insertion and oligomerization. See text for details (from [11]). 
density), and the molecular topology of the monomers and oligomers, in particular the exposure of hydrophobic surfaces, which need to be in contact with the lipid acyl chains. Importantly, these processes also explain why anionic lipids promote membrane intercalation of amphipathic peptides. Accordingly, neutralization of the 'gatekeeping' role Lys and Arg adjacent to amyloidogenic sequences [68] by membrane anionic lipids allows oligomerization, together with efficient intermolecular hydrogen bonding into $\alpha$ - and $\beta$-sheet structures. When these structures are amphipathic, they can intercalate into the bilayer, with $\mathrm{H}-$ bonding alleviating the free energy penalty for accommodating $\mathrm{H}$-bond donors and acceptors into a low dielectric milieu.

vi) The oligomers subsequently adopt a $\beta$-sheet conformation, representing conformational minimum in the folding/aggregation free energy landscape [69]. These $\beta$-state oligomers further aggregate and form more macroscopic fibers and also incorporate lipids derived from the bilayer. These processes however, still remain poorly understood.

Considering the above overall scenario, it is important to bear in mind that several of the above steps (such as $i v$ and $v$ ) are highly connected. Likewise, it is essential to analyze these molecular scale events within the context of the protein folding/aggregation free energy landscape [69], fused with the free energy landscape of the membrane lipid assembly, with particular reference to the driving forces involved. This merging of membranes with proteins adds significantly to the degenerate, multidimensional nature of the amyloid folding/aggregation, the kinetics of fibrillation (eg. nucleation dependent $v s$ independent) being critically influenced by the environment (concentration, temperature, $\mathrm{pH}$, electrolytes) and described by multidimensional phase diagrams [69]. It is likely, for instance, that fibrillation pathways in bulk solution are different from those in membranes.

The above outlined role of lipid surfaces in enhancing amyloid formation represents an important addition to our understanding of the natively unfolded proteins, capable of adopting several conformations and executing different and sometimes unrelated functions, depending on the environment these proteins are brought into. In these respect the lipid surfaces open a plethora of interesting possibilities, particularly when considering the vast chemical diversity available in the lipid species, with cell type and organelle specific lipid compositions. This point of view on lipidomics also emphasizes the importance of understanding the inherent biophysical characteristics of lipid membranes, apart from mere chemical cataloguing of the individual lipid species. To this end, a recent study introduces further complexity to lipid-protein interactions, revealing the role of chemically modified lipid species generated upon ROS attack, such lipids reacting covalently with membrane binding cytotoxic, amyloid forming peptides [70,71].

\section{Protofibrils Puncturing the Lipid Bilayer}

There is current consensus for the mechanism of cytotoxicity of amyloid being due to membrane permeabilization by a transient intermediate state oligomer, 'protofibril' [6-
8,72, 73]. Accordingly, the binding of an amyloidogenic peptide to the lipid bilayer, the subsequent protofibril formation in the membrane, and the mechanism of cytotoxicity of the protofibril, i.e. breaking the permeability barrier function of the involved bilayer are likely to be intimately connected. A key question concerns the structure and biophysical characteristics of the toxic 'protofibril'. In this context it is helpful to recognize that there is recent evidence for the mechanism of cytotoxicity of host defence peptides involving amyloid-like fibers $[10,11,74]$. Likewise, toxicity does not depend on the chirality of the amino acids, as demonstrated for $A \beta$ fragments [75] and the antimicrobial peptide temporin [76]. Further, the toxicity is associated with a large number of diverse sequences, again strongly suggesting that it is a generic feature of proper structural characteristics of the oligomer. Notably, the size of the membrane permeabilizing defects increases with an increasing content of the peptides in the target cell membrane [77], revealing that while channel-like structures could be present, the toxic fibril structures are polydisperse. Based on this we have proposed a model for the minimal possible structure capable of compromising the permeability barrier function of a lipid bilayer (Fig. 6). In this model the length of the oligomer can vary, increasing with the local monomer concentration. While depicted here as linear, also circular structures are possible. The width of the fibril needs to be sufficient ( 35 to $45 \AA$ ) to span the thickness of the bilayer, in particular the hydrophobic region (approx. $20 \AA$ ). Importantly, the fibril also needs to be amphiphilic, with the hydrophobic surface associating efficiently with the hydrocarbon region of the membrane lipids, and the hydrophilic surface forcing a structural, membrane permeabilizing defect into the bilayer. This structure should be highly dynamic, with intense fluctuations in the organization of the opposing high curvature edge of the bilayer (for a linear protein oligomer), also meaning that this protofibril state is transient and seeks progression towards a lower free energy in the folding/aggregation free energy landscape, in combination with the free energy landscape for the organization of lipid bilayer. As long as the fibril is amphiphilic so as to open a 'leaky slit' defect, the conformation of the peptide in the fibril is irrelevant. However, the structure should be metastable (representing an intermediate in the free energy landscape). In this regard it is of interest that an obligatory $\alpha$-helical intermediate has been identified to be involved in the formation of amyloid by some peptides [64,65]. It has also been suggested, that the transient cytotoxic fibrillar intermediate is an $\alpha$-sheet [78], a pleated sheet structure [79,80], which has recently been identified as a relatively common structural element, capable of switching to $\beta$-sheet by peptide plane flipping [81]. To this end, in the light of the above model, it is likely, that several secondary structures of the oligomers could be cytotoxic, as long as the above physicochemical requirements for membrane permeabilization are met.

The transient cytotoxicity of the oligomers complies with the time- and concentration dependence of the effect of e.g. temporin $\mathrm{L}$ on cultured cancer cells, with abrupt levelling off of cell death, with increasing peptide concentrations this discontinuity seen at larger fraction of dead cells (Fig. 7 in [82]). Likewise, the morphological transformation of giant liposome membranes by host defense peptides commences 


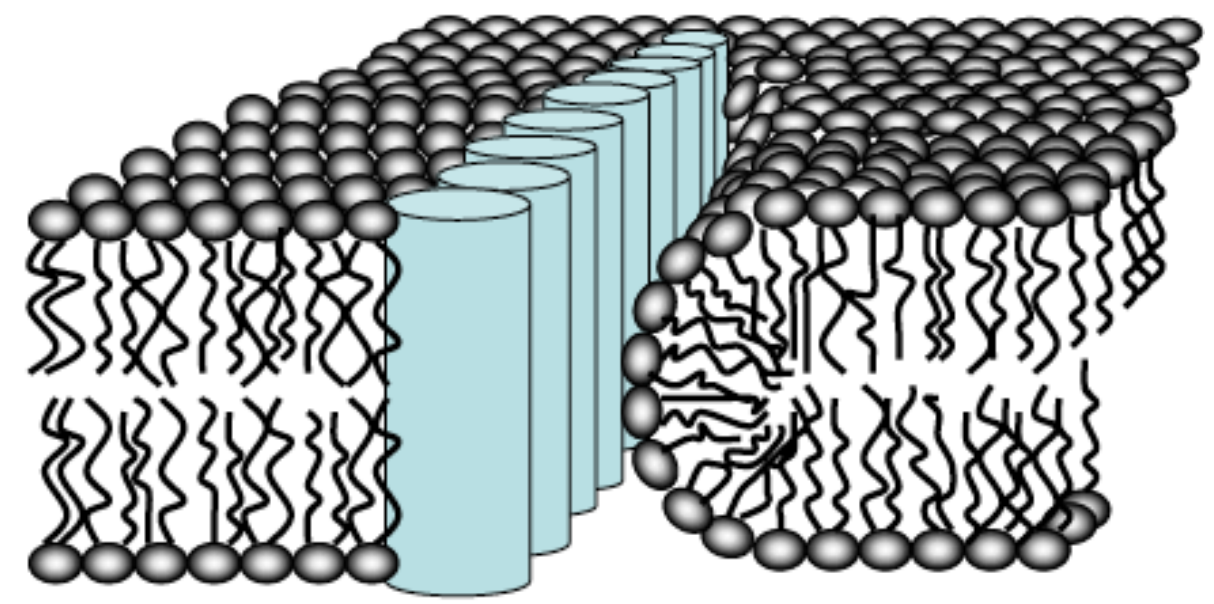

Fig. (6). 'Leaky slit' type linear membrane defect imposed by an amphipathic fibrillar ribbon, consisting of a peptide oligomer (from [59]).

rapidly and is followed by the emergence of seemingly inert, highly refractive aggregates in the affected membrane $[83,84]$. Accordingly, we have emphasized the intermediate nature of the membrane perturbing structures occurring in the course of the initially asymmetrically introduced peptides reacting with the targeted membrane, this system then relaxing towards thermodynamic equilibrium [83]. Interestingly, permeabilization of lipid bilayers by the growing oligomer but not the 'mature' amyloid was recently demonstrated in coarse grained MD simulations [85]. Further, we have shown the incorporation of phospholipids into amyloid fibrils formed in vitro in the presence of liposomes [9]. Subsequently, this was demonstrated also for IAPP and it was further suggested that this lipid uptake could contribute to the membrane permeabilization in the course of the aggregation/fibrillation $[58,86]$.

\section{Molecular Pathology of Amyloid Cytotoxicity: Role of Lipids}

Relating to the mechanisms by which lipid surfaces can enhance amyloid formation - as demonstrated in vitro raises several questions when pursuing the possible roles of lipids in triggering amyloid formation in vivo. A key question concerns the presence of amyloid formation enhancing lipids in the plasma membrane of e.g. neurons. More detailed and specific answers to this issue await results from topological analyses of the lipidome of these cells. Yet, there is evidence for PS being present in the outer surface of neurons. Treatment of isolated neurons by serine decarboxylase, converting PS to PE, reduces the amplitude of the action potential, thus demonstrating a functional role of PS in the operation of the nerve membrane $\mathrm{Na}^{+}$channel [87]. This reaction is reversible and the amplitude could be restored by performing the opposite reaction in the presence of excess serine, driving the conversion of PE to PS. Accordingly, while this author is not aware of quantitative determination of the content of PS in the outer leaflet of the neuron plasma membrane, the above experiments do demonstrate the presence of this lipid at a location, which would be compatible with the emergence of extracellular amyloid deposits in Alzheimer's disease. To this end, the exposure of PS on the outer surface of an axon could represent one of the reasons requiring the isolation of the brain from circulation by the blood-brain barrier.
Apart from PS, Axelsen and coworkers demonstrated augmented formation of amyloid by $A \beta$ peptide in the presence of oxidized phospholipids [88]. Similar findings were reported by Kelly and his coworkers for IAPP and oxidized sterols [70]. These findings could be highly significant, in particular as augmented oxidative stress is associated with Alzheimer's, Parkinson's, and prion diseases, as well as type 2 diabetes $[89,90]$. These findings could also underlie middle body obesity as a risk factor for DM2 [91], with slow fractional lipid turnover of the abdominal fat necessarily increasing lipid peroxidation [92] and subsequent transfer and equilibrium of oxidized lipids through the plasma compartment to all cells. Accordingly, long term presence of oxidized lipids in the Langerhans $\beta$-cell outer surface would readily make these cells vulnerable to amyloidogenic attack by IAPP, present in high concentrations on the surface of the $\beta$-cells following secretion of this peptide by these cells.

\section{Host Defence Proteins/Peptides: Targeting Lipids}

Innate immunity provides the first line of defence in eukaryotic organisms against microbial infection. Important constituents of this host defence are cytotoxic peptides and proteins, secreted by several cell lines, e.g. neutrophils, lymphocytes and natural killer cells. It has also become evident that host defence peptides not only kill bacteria but also eradicate cancer cells [93]. A prominent example of the multifunctional character of these peptides is LL-37, which in addition to being cytotoxic has also chemotactic activity, amongst a number of other functions in organisms, in keeping with LL-37 being a natively disordered protein [94]. Recent studies have demonstrated that augmented formation of amyloid fibrils by acidic lipids is not limited to the paradigm amyloid disease associating peptides but occurs also for several host defence peptides and cytotoxic and apoptotic proteins $[9,10,33,59]$. There is consensus of HDP exerting part of their toxicity by permeabilizing the microbial target cell membrane. The latter are enriched in acidic phospholipids, phosphatidylglycerol and cardiolipin, which promote membrane binding and intercalation of HDP. In a similar manner, some cytolytic HDP specifically permeabilize the cancer cell plasma membrane and can be readily expected to damage also the mitochondrial membrane, inducing apoptosis [93]. An aldehyde functionalized derivative 
from lipid peroxidation, viz. 1-palmitoyl-2-oxononaoyl-snglycero-3-phosphocholine (PoxnoPC) was recently shown to react with several host defence peptides in vitro, most likely involving Schiff base formation [71]. This suggests that for instance macrophages secreting both ROS and HDP at the site of infection would induce the formation of oxidized lipids in microbial membranes, thus making them vulnerable to permeabilization by HDP.

In addition to targeting microbes to HDP, specific lipid compositions appear to also protect the HDP secreting eukaryotic host cells from the membrane damaging action of these peptides. In this regard, while several sterols have been shown to attenuate membrane binding and intercalation of HDP, cholesterol seems to be the most efficient [32]. The most efficient inhibition of HDP-lipid bilayer interaction is obtained by the combination of cholesterol and sphingomyelin [33], the two lipids constituting the bulk of lipid in the eukaryote plasma membrane outer leaflet. Taking into account the threat presented by microbes on eukaryote cell survival from early on in evolution, it is likely that the ability to distinguish microbial targets from the HDP secreting host contributed in a crucial manner to the molecular evolution of cholesterol and the development of HDP resistant lipid compositions of eukaryotes [32]. To this end, the transient cytotoxic amyloid intermediate is indeed ideal for antimicrobial purposes, exerting cytotoxicity only towards cells exposing negatively charged and oxidized lipid, which would trigger amyloid formation in the membrane surrounding the target cell. The cytotoxic intermediate would subsequently be processed to inert, mature amyloid, in essence detoxifying the HDP.

Another example of lipid induced functional formation of cytotoxic amyloid, serving a beneficial function to the organism is provided by endostatin, a $38 \mathrm{kDa}$ domain cleaved from the N-terminus of type XVIII collagen by matrix metalloproteinases. Endostatin efficiently kills cancer cells, however, no specific receptor for this protein was found. Interestingly, endostatin forms amyloid fibrils in vitro and these fibrils were shown to be cytotoxic [95]. We demonstrated endostatin to form in the presence of PS containing liposomes Congo red staining macroscopic fibers [10]. Based on these findings we suggested that endostatin would kill cancer cells by forming cytotoxic amyloid protofibrils in the cancer cell plasma membrane [10]. PS contacting the plasma compartment activates the conversion of prothrombin to thrombin, triggering the coagulation cascade [45]. This process underlies also the Trosseau syndrome: the augmented thrombosis in cancer patients, with accelerated coagulation catalyzed by PS exposed on the outer surface of cancer cells as well as vascular endothelial cells in tumours. The latter change in PS distribution is caused by poorly understood mechanisms in these cells, yet appears to include the prevailing acidic $\mathrm{pH}$ of the affected tissue [96]. The exposure of PS in cancer cells could also explain the decay of tumours in cancer patients with bacterial infection [10]. More specifically, several HDP have been shown to kill also cancer cells in vitro (e.g. [93]). Accordingly, upon bacterial infection the innate immunity generated HDP would then target both microbes as well as PS-exposing cancer cells, together with tumour vascular endothelial cells. In this regard the role of inflammation in cancer tissue and generation of oxidized lipids would definitely warrant further studies, as these lipids could (similarly to representing targets to HDP in bacterial infection) be involved in sensitizing cancer cells to cytotoxic, cancer cell clearing proteins. Notably, this would readily explain the increased incidence of some cancer types upon treatment with an antioxidant, suppressing apoptosis [97].

\section{Amyloid Formation as an on-off Switch for Enzyme Activity}

In addition to lipid-induced formation of cytoxic amyloid fibrils used in the eradication of bacteria and cancer cells, very recent studies from our laboratory suggest that amyloid formation could also be used as an on-off switch controlling enzyme activity. In brief, phospholipase A2 (PLA2) acting on a saturated phospholipid substrate such as 1,2-dipalmitoyl-sn-glycero-3-phosphocholine (DPPC) exerts at temperatures close to the main chain melting phase transition temperature $T_{m}$ of this lipid a pronounced lag phase (for a recent account see [98]). Accordingly, after the rapid binding of PLA2 to the lipid substrate surface, the catalytic rate is initially very low, causing slow accumulation of the lipophilic reaction products, 1-palmitoyl-lysoPC and palmitic acid into the lipid bilayer. However, when a critical content of the products, approx. $8 \mathrm{~mol} \%$ has been formed, there is a sudden burst in hydrolysis, the enzyme becoming highly active. The critical component appears to be lysoPC [98, 99], which binds to PLA2 and could thus cause a conformational change promoting oligomerization. Yet, the fact that a high local content is required suggest that the activation results from a membrane property imposed by this lipid. At this stage the decisive property remains uncertain. Several of the possible features are mutually non-exclusive, such as exemplified by the lateral pressure profile (membrane positive spontaneous curvature [27]) and membrane dipole potential.

Formation of enzyme aggregates has been concluded to be involved in the activation of PLA2 [100,101] and we showed the burst in activity to be accompanied by an enhanced Thioflavin $\mathrm{T}$ fluorescence, followed by the formation of Congo red staining more macroscopic fibrils [98]. Using fluorescently labelled PLA2 we demonstrated FRET between the enzyme to peak at burst and the incorporation of the fluorescent PLA2 into the fibrils. Formation of fibrils was recently demonstrated by AFM as well as fluorescence microscopy, upon observing the action of PLA2 on supported DPPC bilayers [102, 103]. Notably, lipid induced formation of cytotoxic amyloid protofibrils would readily explain the neurotoxicity of catalytically inactive PLA2 proteins, found in some snake venoms [104]. Further, it is likely that amyloid oligomerization induced by a proper lipid environment on the membrane surface represents a common mechanism of activation of membrane bound proteins, lipolytic enzymes, such as sphingomyelinases and e.g. protein kinase C. To this end, our sequence analyses revealed secretory PLA2s to contain short amyloidogenic 'cassettes' (Code C, Mahalka A, Bry K, Kinnunen PKJ, to be published).

PLA2 is activated by A $\beta$ peptide [105], as well as several host defense peptides, such as indolicidin, temporins $\mathrm{B}$ and L, and magainin [106] and for HDP this activation has been 
suggested to contribute to the synergistic cytotoxicity of the combination. The mechanism of this activation is unclear and could involve perturbation of the substrate lipid by these strongly membrane binding peptides. We have recently demonstrated that these peptides could also activate PLA2 by forming heterooligomeric amyloid-type peptide-PLA2 cofibrils [99]. Also this mechanism may well be more generic. For example, it has been shown that the sequence in apolipoprotein C-II interacting and activating lipoprotein lipase [107] does form in the presence of phospholipids amyloid fibrils [108].

\section{Control of Intracellular Membrane Traffic and Cell Shape?}

Recent experiments using supported lipid bilayers as a membrane model demonstrated a dramatic transformation of the membrane topology to be induced by host defense peptides [109]. More specifically, the antimicrobial peptide temporin B caused a rapid outgrowth from the SLB of membrane tubules, consisting of both lipid and the peptide. Accordingly, this readily suggests that similar processes induced by specific peptides could be utilized by cells to induce outgrowth of similar tubular structures, both from the plasma membrane as well as from the intracellular membranes such as Golgi, developing e.g. neurites [110] or serving in the intracellular membrane [111], respectively.

\section{CONCLUDING REMARKS: YING AND YANG OF AMYLOID FORMATION}

The permeability barrier function of lipid bilayers was established very early and remained for a long time the sole functional property assigned to lipids. The picture is now very different and lipids are understood to represent not only a structural constituent but to be actively involved in a variety of membrane functions. While the immense chemical diversity of lipid structures found in biomembranes somewhat overshadows the generic physicochemical principles describing lipid bilayers, it has become obvious that the latter govern in an explicit manner processes such as peptide binding, insertion and oligomerization in membranes. With more structural and kinetic data accumulating it will become possible to decipher the terrain in the protein folding/aggregation free energy landscape, when merged with the free energy landscape for lipid assemblies. These data, together with knowledge about specific short range protein-protein and lipid-protein interactions, with the involved chemistry, will enable to establish effective means to control pathological amyloid formation in biomembranes, the underlying molecular level mechanism of devastating diseases. However, the consequences are likely to be even more far reaching, as recent developments have provided evidence for functional lipid-induced formation of cytotoxic amyloid to be employed for host defence, eradicating both invading microbes as well as malignant cells. Accordingly, detailed understanding of these processes will also allow developing new antibiotics and cancer drugs. Amyloid formation also appears to represent an unprecedented mechanism controlling lipid-associated enzymes, as demonstrated for the activation of PLA2 by changes in lipid composition and by the formation of activator peptide-enzyme cofibrils. Lastly, recent experiments on supported lipid bilayers, demons- trating fast outgrowth of lipid/peptide tubules suggest, that these processes could also be used in intracellular membrane traffic as well as in the control of outgrowth of e.g. neuron fibers [110].

Undoubtedly, when exploring the protein-lipid interface there will be more surprises ahead of us, both in terms of novel biophysics as well as generic biological mechanisms and principles.

\section{ACKNOWLEDGEMENTS}

The author thanks past and present members of HBBG, in particular Chris Code MSc, Ajay Mahalka, MSc, JuhaMatti Alakoskela MD PhD, Mikko Parry MD, Yegor Domanov PhD, Rohit Sood PhD, Juha-Pekka Mattila, MSc, and Vladimir Zamotin PhD for several discussions and Prof. Stephen White (UC Irvine) for kindly providing Fig. (4). HBBG is supported by grants from EU FP6 (Nanoear) and FP7 (Sonodrugs), ESF EuroMEMBRANE, Finnish Academy, and the Sigrid Jusélius Foundation.

\begin{tabular}{|c|c|}
\hline \multicolumn{2}{|c|}{ ABBREVIATIONS } \\
\hline $\mathrm{A} \beta$ & $=$ Alzheimer $\beta$-peptide \\
\hline AMP & $=$ Antimicrobial peptides \\
\hline CL & $=$ Cardiolipin \\
\hline DPPC & $=1,2$-dipalmitoyl-sn-glycero-3-phosphocholine \\
\hline$\varepsilon$ & $=$ Dielectric constant \\
\hline FFA & $=$ Free fatty acid \\
\hline FRET & $=$ Förster-type resonance energy transfer \\
\hline HDP & $=$ Host defence proteins $/$ peptides \\
\hline IAPP & $=$ Islet associated polypeptide (amylin) \\
\hline lysoPC & $=$ Lysophosphatidylcholin \\
\hline MD & $=$ Molecular dynamics \\
\hline $\mathrm{PA}$ & $=$ Phosphatidic acid \\
\hline $\mathrm{PC}$ & $=$ Phosphatidylcholine \\
\hline $\operatorname{PrP}$ & $=$ Prion protein \\
\hline PE & $=$ Phosphatidylethanolamine \\
\hline PI & $=$ Phosphatidylinositol \\
\hline PLA2 & $=$ Phospholipase $\mathrm{A} 2$ \\
\hline POPE & $\begin{aligned}= & \text { 1-Palmitoyl-2-oleoyl-sn-glycero-3- } \\
& \text { phosphoethanolamine }\end{aligned}$ \\
\hline PoxnoPC & $\begin{aligned}= & \text { 1-Palmitoyl-2-oxononaoyl-sn-glycero-3- } \\
& \text { phosphocholine }\end{aligned}$ \\
\hline PS & $=$ Phosphatidylserine \\
\hline SLB & $=$ Supported lipid bilayer \\
\hline ROS & $=$ Reactive oxygen species \\
\hline $\mathrm{T}_{\mathrm{m}}$ & $\begin{array}{l}=\text { Phospholipid main phase transition } \\
\text { temperature }\end{array}$ \\
\hline ГFE & $=$ Trifluoroethanol \\
\hline
\end{tabular}




\section{REFERENCES}

[1] Selkoe DJ. Folding proteins in fatal ways. Nature 2003; 426: 900-4.

[2] Petrosillo G, Casanova G, Matera $M$, et al. Interaction of peroxidized cardiolipin with rat-heart mitochondrial membranes: Induction of permeability transition and cytochrome $\mathrm{c}$ release. FEBS Lett 2006; 580: 6311-6.

[3] Iverson SL, Orrenius S. The cardiolipin-cytochrome c interaction and the mitochondrial regulation of apoptosis. Arch Biochem Biophys 2004; 423: 37-46,

[4] Pepys MB. Amyloidosis. Annu Rev Med 2006; 57: 223-41.

[5] Selkoe DJ. Amyloid $\beta$-protein and the genetics of Alzheimer's disease. J Biol Chem 1996; 271 : 18295-8

[6] Gorbenko GP, Kinnunen PKJ. The role of lipid-protein interactions in amyloid-type protein fibril formation. Chem Phys Lipids 2006; 141: 72-82.

[7] Stefani M. Generic cell dysfunction in neurodegenerative disorders: role of surfaces in early protein misfolding, aggregation, and aggregate cytotoxicity. Neuroscientist 2007; 13: 519-31.

[8] Hebda JA, Miranker AD. The interplay of catalysis and toxicity by amyloid intermediates in lipid bilayers: insights from type 2 diabetes. Ann Rev Biophys 2009; 38: 125-52.

[9] Zhao H, Tuominen EKJ, Kinnunen PKJ. Formation of amyloid fibers triggered by phosphatidylserine-containing membranes. Biochemistry 2004; 43: 10302-7.

[10] Zhao H, Jutila A, Nurminen T, et al. Binding of endostatin to phosphatidylserine-containing membranes and formation of amyloid-like fibers. Biochemistry 2005; 44: 2857-63.

[11] Mahalka AK, Kinnunen PKJ. Binding of amphipathic $\alpha$-helical antimicrobial peptides to lipid membranes: lessons from temporins B and L, Biochim Biophys Acta 2009; 1788: 1600-9.

[12] Kinnunen PKJ. On the principles of functional ordering in biomembranes. Chem Phys Lipids 1991; 57: 375-99.

[13] Stier A, Sackmann E. Spin labels as enzyme substrates. Heterogeneous lipid distribution in liver microsomal membranes. Biochim Biophys Acta 1973; 311: 400-8.

[14] Karnovsky MJ, Kleinfeld AM, Hoover RL, et al. The concept of lipid domains in membranes. J Cell Biol 1982; 94: 1-6.

[15] Estep TN, Mountcastle DB, Barenholz Y, et al. Thermal behavior of synthetic sphingomyelin-cholesterol dispersions. Biochemistry $1979 ; 18: 2112-7$

[16] Goodsaid-Zalduondo F, Rintoul DA, Carlson JC, et al. Luteolysisinduced changes in phase composition and fluidity of bovine luteal cell membranes. Proc Natl Acad Sci USA 1982; 79: 4332-6.

[17] Pietiläinen KH, Sysi-Aho M, Rissanen A, et al. Acquired obesity is associated with changes in theserum lipidomic profile independent of genetic effects - a monozygotic twin study. PLoS One 2007; 2: e218.

[18] Mouritsen OG. Life as a matter of fat - the emerging science of lipidomics. USA: Springer 2007.

[19] Holopainen JM, Subramanian M, Kinnunen PKJ. Sphingomyelinase induces lipid microdomain formation in a fluid phosphatidylcholine/sphingomyelin membrane. Biochemistry 1998; 37: 1756270 .

[20] Israelachvili JN. Intermolecular and surface forces, with applications to colloidal and biological systems. UK: Academic Press 1992.

[21] Disalvo EA, Lairion F, Martini F, et al. Structural and functional properties of hydration and confined water in membrane interfaces. Biochim Biophys Acta 2008; 1778: 2655-70.

[22] Kinnunen PKJ. Lipid bilayers as osmotic response elements. Cell Physiol Biochem 2000; 10: 243-50.

[23] Lehtonen JYA, Kinnunen PKJ. Phospholipase A2 as a mechanosensor. Biophys J 1995; 68: 1888-94.

[24] Kinnunen PKJ. In: On the mechanisms of the lamellar- hexagonal $\mathrm{H}_{\text {II }}$ phase transition and the biological significance of the $\mathrm{H}_{\text {II }}$ propensity. Lasic DD, Barenholz Y, Eds. Nonmedical application of liposomes, USA, Florida: CRC Press 1996; Vol 1, pp. 153-71.

[25] Lehtonen JYA, Kinnunen PKJ. Changes in the lipid dynamics of liposomal membranes induced by poly(ethylene glycol): free volume alterations revealed by inter- and intramolecular excimerforming phospholipid analogs. Biophys J 1994; 66: 1981-90.

[26] Söderlund T, Alakoskela JMI, Pakkanen AL, et al. Comparison of the effects of surface tension and osmotic pressure on the interfacial hydration of a fluid phospholipid bilayer. Biophys J 2003; 85: 2333-41.
[27] Brender JR, Lee EL, Cavitt MA, et al. Amyloid fiber formation and membrane disruption are separate processes localized in two distinct regions of IAPP, the type-2-diabetes-related peptide. J Am Chem Soc 2008; 130: 6424-9.

[28] Kinnunen PKJ. On the molecular-level mechanisms of peripheral protein-membrane interactions induced by lipids forming inverted non-lamellar phases. Chem Phys Lipids 1996; 81: 151-66.

[29] Kinnunen PKJ. Fusion of lipid bilayers: a model involving mechanistic connection to $\mathrm{H}_{\amalg}$ phase forming lipids. Chem Phys Lipids 1992; 63: 251-8.

[30] Kinnunen PKJ, Kõiv A, Lehtonen JYA, et al. Lipid dynamics and peripheral interactions of proteins with membrane surfaces. Chem Phys Lipids 1994; 73: 181-207.

[31] Ipsen JH, Karlström G, Mouritsen OG, et al. Phase equilibria in the phosphatidylcholine-cholesterol system. Biochim Biophys Acta 1987; 905: 162-72.

[32] Sood R, Kinnunen PKJ. Cholesterol, lanosterol, and ergosterol attenuate the membrane association of LL-37(W27F) and temporin L. Biochim Biophys Acta 2008; 1778: 1460-6.

[33] Sood R, Domanov Y, Pietiainen M, et al. Binding of LL-37 to model biomembranes: insight into target vs host cell recognition. Biochim Biophys Acta 2008; 1778: 983-96.

[34] Kinnunen PKJ, Rytömaa M, Kōiv A, et al. Sphingosine-mediated membrane association of DNA and its reversal by phosphatidic acid. Chem Phys Lipids 1993; 66: 75-85.

[35] López-García F, Micol V, Villalaín J, et al. Interaction of sphingosine and stearylamine with phosphatidylserine as studied by DSC and NMR. Biochim Biophys Acta 1993; 1153: 1-8.

[36] Träuble H. Membrane electrostatics. In: Structure and function of biological membranes. Abrahamsson S, Pascher I, Eds. New York: Plenum Press 1977; pp. 509-50.

[37] Parsegian VA. Long-range physical forces in the biological milieu. Annu Rev Biophys Bioeng 1973; 2: 221-55.

[38] Gorbenko GP, Molotkovsky JG, Kinnunen PKJ. Cytochrome c interaction with cardiolipin/phosphatidylcholine model membranes: effect of cardiolipin protonation. Biophys J 2006; 90: 4093-103.

[39] Boström M, Williams DRM, Ninham BW. Influence of Hofmeister effects on surface $\mathrm{pH}$ and binding of peptides to membranes. Langmuir 2002; 18: 8609-15.

[40] Subramanian M, Jutila A, Kinnunen PKJ. Binding and dissociation of cytochrome $\mathrm{c}$ to and from membranes containing acidic phospholipids. Biochemistry 1998; 37: 1394-402.

[41] White SH. How hydrogen bonds shape membrane protein structure. Adv Protein Chem 2006; 72: 157-72.

[42] Thuren T, Tulkki AP, Virtanen JA, et al. Triggering of the activity of phospholipase A2 by an electric field. Biochemistry 1987; 26: 4907-10.

[43] Brockman HL. Dipole potential of lipid membranes. Chem Phys Lipids 1994; 73: 57-79.

[44] Alakoskela JMI, Söderlund T, Holopainen JM, et al. Dipole potential and head-group spacing are determinants for the membrane partitioning of pregnanolone. Mol Pharmacol 2004; 66: 161-8.

[45] Zwaal RFA, Comfurius P, Bevers EM. Surface exposure of phosphatidylserine in pathological cells. Cell Mol Life Sci 2005; 62: 971-88.

[46] Lehtonen JYA, Holopainen JM, Kinnunen PKJ. Evidence for the formation of microdomains in liquid crystalline large unilamellar vesicles caused by hydrophobic mismatch of the constituent phospholipids. Biophys J 1996; 70: 1753-60.

[47] Lehtonen JYA, Kinnunen PKJ. Evidence for phospholipid microdomain formation in liquid crystalline liposomes reconstituted with Escherichia coli lactose permease. Biophys J 1997; 72: 1247 57.

[48] Lehtonen JYA, Kinnunen PKJ. Poly(ethylene glycol)-induced and temperature-dependent phase separation in fluid binary phospholipid membranes. Biophys J 1995; 68: 525-35.

[49] Mustonen P, Virtanen JA, Somerharju PJ, et al. Binding of cytochrome $\mathrm{c}$ to liposomes as revealed by the quenching of fluorescence from pyrene-labeled phospholipids. Biochemistry 1987; 26: 2991-7.

[50] Eklund KK, Kinnunen PKJ. Effects of polyamines on the thermotropic behaviour of dipalmitoylphosphatidylglycerol. Chem Phys Lipids 1986; 39: 109-17.

[51] Eklund KK, Vuorinen J, Mikkola J, et al. Calcium-induced latera phase separation in phosphatidic acid/phosphatidylcholine 
monolayers as revealed by fluorescence microscopy. Biochemistry 1988; $27: 3433-7$.

[52] Sankaram MB, Thompson TE. Cholesterol -induced fluid-phase immiscibility in membranes. Proc Natl Acad Sci USA 1991; 88: 8686-90.

[53] de Almeida RFM, Fedorov A, Prieto M Sphingomyelin/ phosphatidyl-choline/cholesterol phase diagram: boundaries and composition of lipid rafts. Biophys J 2003; 85: 2406-16.

[54] Silva LC, Futerman AH, Prieto M. Lipid raft composition modulates sphingomyelinase activity and ceramide-induced membrane physical alterations. Biophys J 2009; 96: 3210-22.

[55] Holopainen JM, Lemmich J, Richter F, et al. Dimyristoylphosphatidylcholine/ C16:0 -ceramide binary liposomes studied by differential scanning calorimetry and wide- and small-angle X-ray scattering. Biophys J 2000; 78: 2459-69.

[56] Holopainen JM, Metso AJ, Mattila JP, et al. Evidence for the lack of a specific interaction between cholesterol and sphingomyelin. Biophys J 2004; 86: 1510-20.

[57] Chiti F, Webster P, Taddei N, et al. Designing conditions for in vitro formation of amyloid protofilaments and fibrils. Proc Natl Acad Sci USA 1999; 96: 3590-4.

[58] Sparr E, Engel MF, Sakharov DV, et al. Islet amyloid polypeptideinduced membrane leakage involves uptake of lipids by forming amyloid fibers. FEBS Lett 2004; 577: 117-20.

[59] Zhao H, Sood R, Jutila A, et al. Interaction of the antimicrobial peptide pheromone Plantaricin A with model membranes: Implications for a novel mechanism of action. Biochim Biophys Acta 2006; 1758: 1461-74.

[60] Domanov YA, Kinnunen PKJ. Islet amyloid polypeptide forms rigid lipid-protein amyloid fibrils on supported phospholipid bilayers. J Mol Biol 2008; 376: 42-54

[61] Finkelstein AV, Ptitsyn OB. Protein physics. UK: Academic Press 2002.

[62] Hirsch AKH, Fischer FR, Diederich F. Phosphate recognition in structural biology. Angew Chem Int Engl 2007; 46: 338-52.

[63] Knight JD, Hebda JA, Miranker AD. Conserved and sooperative assembly of membrane bound alpha-helical states of islet amyloid polypeptide. Biochemistry 2006; 45: 9496-508.

[64] Kirkitadze MD, Condron MM, Teplow DB. Identification and characterization of key kinetic intermediates in amyloid betaprotein fibrillogenesis. J Mol Biol 2001; 312: 1103-19.

[65] Klimov DK, Thirumalai D. Dissecting the assembly of Abeta16-22 amyloid peptides into antiparallel beta sheets. Structure 2003; 11: 295-307.

[66] Knight JD, Miranker AD. Phospholipid catalysis of diabetic amyloid assembly. J Mol Biol 2004; 341: 1175-87.

[67] Wimley WV, White SH. Reversible unfolding of $\beta$-sheet in membranes: a calorimetric study. J Mol Biol 2004; 342: 703-11.

[68] Rousseau F, Serrano L, Schymkowitz JW. How evolutionary pressure against protein aggregation shaped chaperone specificity? J Mol Biol 2006; 355: 1037-47.

[69] Jahn TR, Radford SE. Folding versus aggregation: Polypeptide conformations on competing pathways. Arch Biochem Biophys 2008; 269: 100-17.

[70] Bieschke J, Zhang Q, Bosco DA, et al. Small molecule oxidation products trigger disease-associated protein misfolding. Acc Chem Res 2006; 39: 611-9.

[71] Mattila JP, Sabatini K, Kinnunen PKJ. Oxidized phospholipids as potential molecular targets for antimicrobial peptides. Biochim Biophys Acta 2008; 1778: 2041-50.

[72] Dobson CM. Protein folding and misfolding. Nature 2003; 426: 884-90.

[73] Kayed R, Sokolov Y, Edmonds B, et al. Permeabilization of lipid bilayers is a common conformation-dependent activity of soluble amyloid oligomers in protein misfolding diseases. J Biol Chem 2004; 279: 46363-6.

[74] Sood R, Domanov Y, Kinnunen PKJ. Fluorescent temporin B derivative and its binding to liposomes. J Fluoresc 2007; 17: 22334.

[75] Pastor MT, Kummerer N, Schubert V, et al. Amyloid toxicity is independent of polypeptide sequence, length and chirality. J Mol Biol 2008; 375: 695-707.

[76] Wade D, Silberring J, Soliymani R, et al. Antibacterial activities of temporin A analogs. FEBS Lett 2000; 479: 6-9.

[77] Kourie JI, Shorthouse AA. Properties of cytotoxic peptide-formed ion channels. Am J Physiol Cell Physiol 2000; 278: C1063-87.
[78] Daggett V. Alpha-sheet: the toxic conformer in amyloid diseases? Acc Chem Res 2006; 39: 594-602.

[79] Pauling L, Corey RB. The pleated sheet, a new layer configuration of polypeptide chains. Proc Natl Acad Sci USA 1951; 37: 251-6.

[80] Pauling L, Corey RB. Configurations of polypeptide chains with favoured orientations around single bonds: two new pleated sheets. Proc Natl Acad Sci USA 1951; 37: 729-40.

[81] Milner-White EJ, Watson JD, Qi G, et al. Amyloid formation may involve $\alpha$ - to $\beta$ sheet interconversion via peptide chain flipping. Structure 2006; 14: 1369-76.

[82] Rinaldi AC, Mangoni ML, Rufo A, et al. Temporin L: antimicrobial, haemolytic and cytotoxic activities, and effects on membrane permeabilization in lipid vesicles. Biochem J 2002; 368: 91-100

[83] Zhao H, Rinaldi AC, Di Giulio A, et al. Interactions of the antimicrobial peptides temporins with model biomembranes. Comparison of temporin B and L. Biochemistry 2002; 41: 4425-36.

[84] Zhao H, Mattila J-P, Holopainen JM, et al. Comparison of the membrane association of two antimicrobial peptides, magainin 2 and indolicidin. Biophys J 2001; 81: 2979-91.

[85] Friedman R, Pellarin R, Caflisch A. Amyloid aggregation on lipid bilayers and its impact on membrane permeability. J Mol Biol 2008; 387: 407-15.

[86] Engel MFM, Khemtmourian L, Kleijer C, et al. Membrane damage by human islet amyloid polypeptide through fibril growth at the membrane. Proc Natl Acad Sci USA 2008; 105: 6033-8.

[87] Cook AM, Low E, Ishijimi M. Effect of phosphatidylserine decarboxylase on neural excitation. Nature 1972; 239: 150-1.

[88] Koppaka V, Paul C, Murray IV, et al. Early synergy between Abeta42 and oxidatively damaged membranes in promoting amyloid fibril formation by Abeta40, J Biol Chem 2003; 278: 36277-84.

[89] Sayre LM, Perry G, Smith MA. Oxidative stress and neurotoxicity Chem Res Toxicol 2008; 21: 172-88.

[90] Evans JL, Goldfine ID, Maddux BA, et al. Oxidative stress and stress-activated signaling pathways: a unifying hypothesis of type 2 diabetes. Endocr Rev 2002; 23: 599-622.

[91] Alberti KG, Zimmet P, Shaw J, et al. The metabolic syndrome-a new worldwide definition. Lancet 2005; 366: 1059-62.

[92] Furukawa S, Fujita T, Shimabukuro M, et al. Increased oxidative stress in obesity and its impact on metabolic syndrome. J Clin Invest 2004; 114: 1752-61

[93] Hoskin DW, Ramamoorthy A. Studies on anticancer activities of antimicrobial peptides. Biochim Biophys Acta 2008; 1778: 357-75.

[94] Uversky VN, Oldfield CJ, Dunker AK. Intrinsically disordered proteins in human diseases: introducing the D2 concept. Annu Rev Biophys 2008; 37: 215-46.

[95] Kranenburg O, Kroon-Batenburg LM, Reijerkerk A, et al. Recombinant endostatin forms amyloid fibrils that bind and are cytotoxic to murine neuroblastoma cells in vitro. FEBS Lett 2003; 539: 149-55.

[96] Ran S, Thorpe PE. Phosphatidylserine is a marker of tumor vasculature and a potential target for cancer imaging and therapy. Int J Radiat Oncol Biol Phys 2002; 54: 1479-84.

[97] Zeisel SH. Antioxidants suppress apoptosis. J Nutr 2004; 134 3179S-80S.

[98] Code C, Domanov Y, Jutila A, et al. Amyloid-type fiber formation in control of enzyme action: interfacial activation of phospholipases A2. Biophys J 2008; 95: 215-24.

[99] Code C, Domanov Y, Killian JA, et al. Activation of phospholipase $\mathrm{A}_{2}$ by temporin $\mathrm{B}$ : formation of antimicrobial peptide-enzyme amyloid-type cofibrils. Biochim Biophys Acta 2009; 1788: 106472.

[100] Hille JD, Egmond MR, Dijkman R, et al. Aggregation of porcine pancreatic phospholipase A2 and its zymogen induced by submicellar concentrations of negatively charged detergents. Biochemistry 1983; 22: 5347-53.

[101] Hazlett TL, Deems RA, Dennis EA. Activation, aggregation, inhibition and the mechanism of phospholipase A2. Adv Exp Med Biol 1990; 279: 49-64.

[102] Chibowski E, Holysz L, Jurak M. Effect of a lipolytic enzyme on wettability and topography of phospholipid layers deposited on solid support. Colloid Surf A 2008; 321: 131-6.

[103] Chiu CR, Huang WN, Wu WG, et al. Fluorescence single-molecule study of cobra phospholipase $\mathrm{A}_{2}$ action on a supported gel-phase lipid bilayer. Chem Phys Chem 2009; 10: 549-58. 
[104] Tsai IH. Evolutionary reduction of enzymatic activities of snake venom phospholipases. Toxicol Rev 2007; 26: 123-42.

[105] Lehtonen JYA, Kinnunen PKJ. Activation of phospholipases A2 by A $\beta$ peptides in vitro. Biochemistry 1996; 35: 9407-14.

[106] Zhao H, Kinnunen PKJ. Modulation of the activity of secretory phospholipase A2 by antimicrobial peptides. Antimicrob Agents Chemother 2003; 47: 965-71.

[107] Kinnunen PKJ, Jackson RL, Smith LC, et al. Activation of lipoprotein lipase by native and synthetic fragments of human plasma apolipoprotein C-II. Proc Natl Acad Sci USA 1977; 74 : 4848-51.
[108] Wilson LM, Mok YF, Binger KJ, et al. A structural core within apolipoprotein C-II amyloid fibrils identified using hydrogen exchange and proteolysis. J Mol Biol 2007; 366: 1639-51.

[109] Domanov YA, Kinnunen PKJ. Antimicrobial peptides temporins B and $\mathrm{L}$ induce formation of tubular lipid protrusions from supported phospholipid bilayers. Biophys J 2006; 91: 4427-39.

[110] Liesi P, Närvänen A, Soos J, et al. Identification of a neurite outgrowth-promoting domain of laminin using synthetic peptides. FEBS Lett 1989; 244: 141-8.

[111] Mironov AA, Beznoussenko GV, Polishchuk RS, et al. Intra-Golgi transport: a way to a new paradigm? Biochim Biophys Acta 2005; 1744: $340-50$.

(C) Paavo K.J. Kinnunen; Licensee Bentham Open.

This is an open access article licensed under the terms of the Creative Commons Attribution Non-Commercial License (http://creativecommons.org/licenses/by$\mathrm{nc} / 3.0 /$ ), which permits unrestricted, non-commercial use, distribution and reproduction in any medium, provided the work is properly cited. 